\title{
A Randomized, Crossover, Adhesion Performance and Pharmacokinetic Study of a Lidocaine Topical System Under Conditions of Water Exposure in Healthy Subjects
}

\author{
Kip Vought' \\ Emileigh Greuber' \\ Kalpana Patel' \\ Charles Argoff ${ }^{2}$ \\ Dmitri Lissin'
}

'Global Research and Development and Medical Affairs, Scilex Pharmaceuticals Inc., Palo Alto, CA, USA; ${ }^{2}$ Department of Neurology, Albany Medical Center, Albany, NY, USA
Correspondence: Dmitri Lissin

Email dlissin@scilexpharma.com
Purpose: This study compares the adhesion performance, pharmacokinetic profile, and safety of lidocaine topical system $1.8 \%$, which is approved to treat postherpetic neuralgia, under conditions of swimming and showering versus normal conditions.

Patients and Methods: This open-label, 3-period, 3-treatment crossover study randomized 24 healthy adults to receive one lidocaine topical system during each of three treatment periods; subjects either swam in a heated swimming pool for 15 minutes 4.0 hours post-product application (swimming), showered for 10 minutes 8.0 hours after product application (showering), or the product remained dry throughout the treatment period (normal conditions). The product was applied to the mid-upper back and was removed after 12 hours. The pharmacokinetic profile of each subject under water exposure conditions was compared to subjects under normal conditions. Skin irritation, adhesion, and adverse events were assessed.

Results: Twenty-four (24) subjects enrolled and 23 completed the study. Exposure to water resulted in lifting of the topical systems. There were two complete detachments, as well as seven occurrences of major lifting (more than 50\% detached) after water exposure. The topical systems were immediately pressed down and/or reapplied after observing lifting and remained adhered to for the rest of the 12-hour application period. No clinically relevant differences in systemic absorption were observed under either showering or swimming conditions. The topical systems were well tolerated, with only mild adverse events, none leading to discontinuation.

Conclusion: These data show that while water exposure can cause the topical system to lift or detach, the lidocaine topical system $1.8 \%$ is capable of being reapplied and maintains adhesion for up to 12 hours of wear with no clinically significant changes in drug delivery. Clinicaltrials.gov: NCT04784728.

Keywords: lidocaine topical system, postherpetic neuralgia, adhesion, water exposure

\section{Introduction}

Topical systems, commonly referred to as patches, containing lidocaine are a wellestablished treatment for pain associated with postherpetic neuralgia (PHN) and other neuropathic pain conditions. ${ }^{1,2}$ Lidocaine is an amide local anesthetic agent that stabilizes neuronal membranes by blocking voltage-gated sodium channels, which are required for initiation and conduction of impulses. A novel lidocaine topical system (ZTlido ${ }^{\circledR}$, Scilex Pharmaceuticals Inc., Palo Alto, CA, USA) was approved by the United States Food and Drug Administration (FDA) for the relief of pain associated with PHN in 2018. Each 
topical system contains $36 \mathrm{mg}$ of lidocaine in a thin, nonaqueous adhesive matrix (18 mg per gram adhesive: $1.8 \%$ ), with $10 \times 14 \mathrm{~cm}$ dimension and $0.08 \mathrm{~cm}$ thickness. ${ }^{3}$ Lidocaine topical system $1.8 \%$ was developed to deliver a bioequivalent level of drug as Lidoderm $^{\circledR}$ (lidocaine patch 5\%; Endo Pharmaceuticals, Malvern, PA, USA), a hydrogel patch containing $700 \mathrm{mg}$ of lidocaine, which is also indicated for the treatment of PHN. ${ }^{4}$

Lidocaine topical systems provide drug directly to the site of pain with low systemic exposure and therefore avoid some of the disadvantages of oral pain management therapies. This is important given the potential for adverse events (AEs) with oral medications used for PHN including serotonin reuptake inhibitors, tricyclic antidepressants, gabapentinoids, anticonvulsants, and opioids. ${ }^{5,6}$ However, optimal drug delivery from a topical system can only be achieved if the system adheres to the skin. Lack of adhesion can compromise drug delivery resulting in poor compliance due to early treatment abandonment. $^{7,8}$

Regulatory agencies recommend evaluating the adhesion of topical systems to support drug approval and recognize in vivo adhesion studies as the most meaningful predictors of commercial drug product performance. ${ }^{9,10}$ Adhesion performance may be challenged by many real-world use conditions. In vitro and in vivo data have shown that external heat application can increase absorption of transdermal and topical drugs, including lidocaine. ${ }^{11,12}$ Exercise also can affect drug absorption, but previous studies with the lidocaine topical system $1.8 \%$ have shown moderate exercise does not have a major effect on drug absorption despite a small degree of product lifting. ${ }^{12}$ Water exposure is another variable that may compromise adhesion and the higher temperatures associated with bathing and showering could affect drug delivery.

The impact of water stress on the adhesion and pharmacokinetics of lidocaine, delivered using the lidocaine topical system $1.8 \%$, is currently unknown. In fact, these products are labeled so that the patient should avoid getting the product wet due to unknown effects. The primary objective of this study was to evaluate the adhesion of the topical system during and after showering or swimming. The secondary objectives were to evaluate lidocaine pharmacokinetics and tolerability of the topical system under the same conditions.

\section{Materials and Methods}

\section{Measures and Outcomes}

This open-label, randomized, 3-treatment, 3-sequence, 3-period crossover study was conducted at one clinical site (AXIS Clinicals, Dilworth, MN, USA), approved by Salus Institutional Review Board (IRB), and conducted in accordance with the Declaration of Helsinki. Informed consent was obtained from all study participants. This study was registered with ClinicalTrials.gov, NCT04784728.

\section{Study Objectives}

The primary objective of this study was to evaluate the adhesion performance of lidocaine topical system $1.8 \%$ in fasting healthy human subjects during swimming, showering, and normal (dry) conditions. The secondary objectives were to determine the pharmacokinetics (PK) of lidocaine topical system $1.8 \%$ under two water stress and normal conditions. Tolerability of the topical system under water conditions vs normal conditions was also assessed.

\section{Subjects}

Eligible men and women were 18-60 years of age, with a body mass index (BMI) between 18.00 and $30.00 \mathrm{~kg} / \mathrm{m}^{2}$. Subjects assessed to be in a healthy condition were based on pre-study medical examination, clinical laboratory tests, vital sign assessments, and 12-lead electrocardiogram. Subjects had to be capable of swimming unassisted. Female subjects were not pregnant and used contraception during the study if they were of child-bearing potential. All subjects provided written informed consent and were able to comply with study procedures.

\section{Exclusion Criteria}

Subjects were excluded if they had any major medical illness 3 months prior or any significant chronic medical illness. Subjects with allergies or known hypersensitivity to lidocaine, amide-type local anesthetics, or components of the product formulation were excluded as were subjects with conditions that might affect application of the product or its adhesive properties (including psoriasis, eczema, atopic dermatitis, damaged or irritated epidermal layer, and excessive hair or oil on the skin). History of addiction, abuse, and misuse of any drug; use of any nicotinecontaining products within 30 days; or alcohol abuse within 12 months prior to product application were also reasons for exclusion.

\section{Treatments}

Per randomization schedule, all subjects received one lidocaine topical system $1.8 \%$, containing $36 \mathrm{mg}$ of lidocaine, during three separate treatment periods (Period-I, Period- 
II, Period-III). Each period included eight subjects per treatment. Subjects were randomized to three different treatment sequences. In each period, one topical system was applied to clean, dry skin that was free of lotion, soap, or oil to the mid-upper back after an overnight fast $(\geq 10$ hours) in each of the three randomly allocated treatment plans, with a 4-day washout between treatments. The topical system was worn for 12 hours in each treatment period. No overlays, adhesive tape, or similar products were applied. The treatments included:

- 1 lidocaine topical system $1.8 \%$ with swimming

- 1 lidocaine topical system 1.8\% with showering

- 1 lidocaine topical system $1.8 \%$ under normal conditions

\section{Swimming}

Subjects swam in a $24 \times 36$ feet pool with a depth of 3 to 5 feet (maintained at $80-85^{\circ} \mathrm{F}$ ) for 15 minutes four hours after topical system application. Subjects were instructed to swim two lengths of the pool at the shallow end and were allowed to stop and stand as needed. The remainder of the time involved continuous walking or swimming with the topical system completely immersed under water. After the swim period, subjects exited the pool, rinsed off with running water for no more than 3 minutes, patted dry and dressed, taking care to avoid rolling the topical system. The topical system was patted dry by the staff.

\section{Showering}

Subjects showered at the Axis facility 8 hours after the topical system was applied. Subjects were instructed to carefully disrobe to their bathing suits, taking care not to lift or dislodge the topical system. The bathing suits were not allowed to cover or otherwise restrict the topical systems. Subjects showered for 10 minutes, washing and rinsing normally. Soap, shampoo and conditioner were supplied to the subjects. At the end of the shower period, subjects exited the shower and dried as they normally would, taking care not to rub the topical system. The topical system was patted dry by the staff.

The swimming duration of 15 minutes was established based on a suitable time for subjects to enter the water, immerse and engage in swimming movements, and exit the water. The showering time of 10 minutes was established based on the estimated time for subjects to wash and condition hair, and wash their body.

\section{Study Assessments}

Product adhesion was assessed immediately after ( 0 hours) and at $3,4.5,7,8.5$, and 12 hours (before system removal) after application. The 4.5- and 8.5-hour time points were selected in order to obtain an assessment shortly after the water exposure activities had been completed. In addition, unscheduled, ad hoc adhesion assessments were performed during the water immersion activities only if a subject observed, or study staff observed, or felt that their topical system was lifting. In those cases, study staff examined the subject, scored the adhesion at the time of lifting, and then pressed the topical system back onto the skin to readhere it. No tape or overlays were allowed during the study and no additional pressing was allowed by either subjects or clinical staff before or after the water stress activity throughout the 12-hour treatment periods. Adhesion was evaluated by trained staff using the dot matrix method as previously described. ${ }^{13}$ Briefly, the degree of adhesion was assessed by a trained scorer using a transparent grid with evenly spaced dots. The grid was demarcated to the exact size of the topical system. The dot matrix grid was gently laid over the product on the skin, and areas of adhesion were outlined; dots excluded from adhering areas were counted to identify the exact surface area of lift-off and allowing the determination of the total amount of product adhesion as a percentage (ie, percent adhesion).

The PK of each treatment condition was evaluated by estimation of lidocaine concentrations in plasma, using a validated liquid chromatography-tandem mass spectrometry (LC-MS/MS) method. The calibration range of the procedure was $0.2000 \mathrm{ng} / \mathrm{mL}$ to $200.0 \mathrm{ng} / \mathrm{mL}$, with a lower limit of quantification of $0.2000 \mathrm{ng} / \mathrm{mL}$. PK parameters such as maximum plasma concentration $\left(\mathrm{C}_{\max }\right)$, area under the plasma concentration-time curve between times zero and $\mathrm{t}\left(\mathrm{AUC}_{0-\mathrm{t}}\right)$, AUC between time zero and infinity $\left(\mathrm{AUC}_{0-\infty}\right)$, time to $\mathrm{C}_{\max }\left(\mathrm{t}_{\max }\right)$, percentage extrapolation (calculated as $\mathrm{AUC}_{\% \text { extrapolation }}=\left[\mathrm{AUC}_{0-\infty}-\mathrm{AUC}_{0-\mathrm{t}}\right]$ $\left.\times 100 / \mathrm{AUC}_{0-\infty}\right)$, elimination rate constant $\left(\mathrm{K}_{\mathrm{el}}\right)$, and elimination half-life $\left(\mathrm{t}_{1 / 2}\right)$ were calculated following blood collection by venipuncture pre-dose and at 1.5, 3, 6, 9, $12,15,18$, and 24 hours post-dose.

Skin irritation at the lidocaine topical system application site was evaluated pre-application ( 0 hours), 30 minutes (with a window period of \pm 15 minutes) after product removal and 2 hours (with a window period of \pm 15 minutes) after product removal using the FDA-recommended 8-point scale of dermal response $(0=$ no evidence of irritation; $1=$ minimal 
erythema, barely perceptible; 2=definite erythema; $3=$ erythema and papules/pustules; 4=definite edema; 5=erythema, edema, and papules; 6=vesicular eruption; $7=$ strong reaction spreading beyond the test site) and a scale of other effects (including glazed appearance, peeling and cracking, dried serous exudates covering at least part of the application site, and small petechial erosions and/or scabs). ${ }^{14}$

\section{Statistical Analysis}

The randomization schedule was prepared using $\mathrm{SAS}^{\circledR}$ Release 9.4 (SAS Institute Inc., Cary, NC, USA). Data set preparation and analysis of the $\mathrm{PK}$ parameters were performed using a non-compartmental model with Phoenix WinNonlin $^{\circledR}$ Professional Software version 8.0 (Certara USA, Princeton, NJ, USA). The sample size $(n=24)$ was chosen based on previous adhesion performance studies with the product. ${ }^{13}$

Descriptive statistics were computed for all PK parameters for lidocaine topical system $1.8 \%$ (total lidocaine dose $=36 \mathrm{mg}$ ) under each treatment condition (swimming, showering, and normal). Comparison of PK parameters for the water exposure conditions vs normal conditions was carried out using Mixed Effect ANOVA (PROC MIXED) of SAS ${ }^{\circledR}$ Release 9.4. Analysis of variance was calculated for untransformed and natural log-transformed $\mathrm{C}_{\max }, \mathrm{AUC}_{0-\mathrm{t}}$, and $\mathrm{AUC}_{0-\infty}$ using the treatment received, the period at which it was given, the sequence of treatment, and the subject effect (nested within the sequence). Sequence effect was tested using the subject nested within sequence mean square from the ANOVA as the error term. ANOVA calculations included least square mean. The level of significance was set at $\alpha=0.05$. Ratio analysis was computed for ln-transformed $\mathrm{PK}$ parameters of lidocaine $\mathrm{C}_{\max }, \mathrm{AUC}_{0-\mathrm{t}}$, and $\mathrm{AUC}_{0-\infty}$ data. A 90\% confidence interval for the ratio of the water conditions vs normal conditions averages were calculated using the least squares means for lntransformed $\mathrm{C}_{\max }, \mathrm{AUC}_{0-\mathrm{t}}$, and $\mathrm{AUC}_{0-\infty}$.

\section{Adverse Events and Safety}

Adverse events (AEs) were recorded and subsequently coded in tabular form using the MedDRA Version 22.0 adverse event dictionary.

\section{Results}

\section{Subject Disposition and Baseline Characteristics}

A total of 24 subjects, aged between 22 and 60 years with BMI values between 19.94 and $29.96 \mathrm{~kg} / \mathrm{m}^{2}$
Table I Demographics and Baseline Characteristics

\begin{tabular}{|l|c|}
\hline & $\mathbf{N}=\mathbf{2 4}$ \\
\hline Age, years, mean \pm SD (range) & $37.21 \pm 13.26(22-60)$ \\
\hline Sex, $\mathrm{n}, \mathrm{M} / \mathrm{F}$ & $\mathrm{I} / \mathrm{II}$ \\
\hline Race, $\mathrm{n}(\%)$ & $16(66.7 \%)$ \\
White & $6(25.0 \%)$ \\
Black & $\mathrm{I}(4.2 \%)$ \\
Asian & $\mathrm{I}(4.2 \%)$ \\
American Indian/Alaska Native & $25.0 \mathrm{I} \pm 2.88(19.94-29.96)$ \\
\hline BMI, kg/m², mean \pm SD (range)
\end{tabular}

Abbreviations: SD, standard deviation; BMI, body mass index.

(Table 1), were enrolled in the study. Subjects were randomized to each of the 3 treatment sequences according to the predetermined schedule; one subject withdrew after the first period. All subjects were included in the adhesion analysis; plasma concentrations of 24 subjects were included in PK analysis and 23 subjects were included in statistical analysis of lidocaine.

\section{Adhesion Analysis}

Lidocaine topical systems were observed to have increased lifting during the water exposures. Thirteen out of 23 subjects (57\%) experienced product lifting during the swimming activity and 4 out of 24 subjects (17\%) experienced product lifting during the showering period (Table 2). There were occurrences of major lifting (> 50\% lifting) during the swimming and showering periods, including two complete detachments during the showering exposure period. All topical systems that were observed to be lifting or that had detached completely were successfully pressed back down or reapplied and there were no complete detachments observed for the remainder of the administration period. In fact, mean adhesion was $>90 \%$ for all treatments at the end of the 12-hour administration period

Table 2 Summary of Subjects with Topical System Lifting or Detachment

\begin{tabular}{|l|c|c|c|}
\hline Treatment & $\mathbf{N}$ & $\begin{array}{c}\text { No. Subjects } \\
\text { with Lifting } \\
\text { (\%) }\end{array}$ & $\begin{array}{c}\text { No. Subjects with } \\
\text { Complete Detachment } \\
\text { (\%) }\end{array}$ \\
\hline Swimming & 23 & $13(57 \%)$ & 0 \\
Showering & 24 & $4(17 \%)$ & $2(8 \%)$ \\
Normal & 23 & 0 & 0 \\
\hline
\end{tabular}




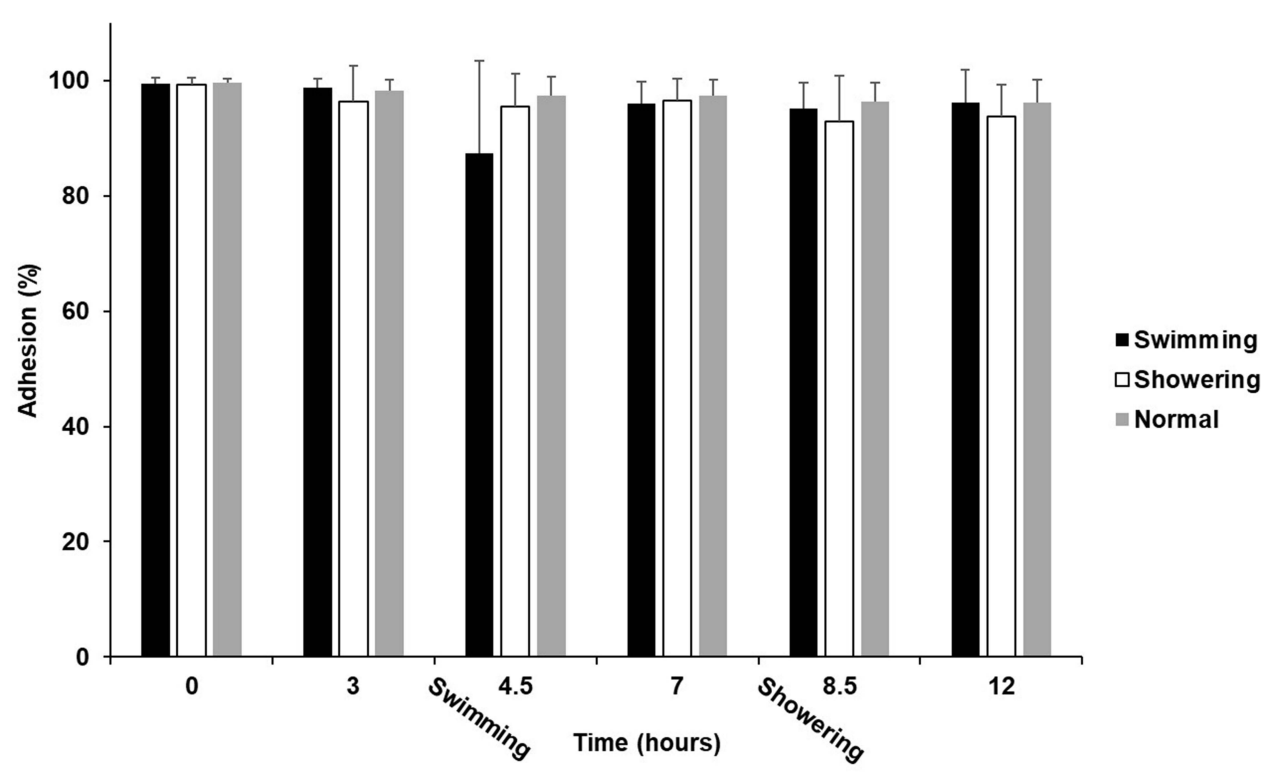

Figure I Adhesion of lidocaine topical system I.8\% over time under swimming, showering, and normal conditions. Adhesion scores were evaluated at $0,3,4.5,7,8.5$ and I2 hours after application. The 4.5- and 8.5-hour time points were selected to obtain an assessment shortly after the water exposure activities had completed. Mean adhesion was $>90 \%$ for all treatments at the end of 12 -hour administration.

(Figure 1). Descriptive statistics for the mean percentage adhered to data as calculated from the dot matrix scoring approach are shown in Table 3.

\section{PK Assessments}

Summary statistics for lidocaine pharmacokinetic parameters are presented in Table 4 and in Figure 2. Comparable pharmacokinetics were observed for lidocaine topical system $1.8 \%$ under normal and water stress treatments. The mean (SD) peak plasma concentration and $\mathrm{AUC}_{0-\mathrm{t}}$ of $18.8 \pm 6.5 \mathrm{ng} / \mathrm{mL}$ and $249.4 \pm$ $88.2 \mathrm{ng} \cdot \mathrm{hr} / \mathrm{mL}$ under swimming conditions, and $27.2 \pm$ $19.0 \mathrm{ng} / \mathrm{mL}$ and $338.7 \pm 215.9 \mathrm{ng} \cdot \mathrm{hr} / \mathrm{mL}$ under showering conditions, versus $24.5 \pm 11.1 \mathrm{ng} / \mathrm{mL}$ and $323.3 \pm$ $153.3 \mathrm{ng} \cdot \mathrm{hr} / \mathrm{mL}$ under normal conditions.

By comparing showering to normal conditions, the $90 \%$ confidence intervals for geometric least square means of $1 n$-transformed data of $\mathrm{C}_{\max }$ and $\mathrm{AUC}_{0-\mathrm{t}}$ of lidocaine were within the bioequivalence acceptance range (80.00-125.00\%), but the 90\% confidence intervals for geometric least square means of ln-transformed data of $\mathrm{AUC}_{0-\infty}$ of lidocaine was outside the range (74.64-102.52) (see Table 5). This may be due in part to the small sample size; only 7 subjects could be analyzed for $\mathrm{AUC}_{0-\infty}$, because a log-linear relationship was not observed in the terminal elimination phase in the concentration vs time profile of 15 subjects and were subsequently excluded from the calculations. None of the pharmacokinetic parameters fell within the bioequivalence criteria for swimming vs normal conditions (see Table 5). The mean $\mathrm{C}_{\max }$, $\mathrm{AUC}_{0-\mathrm{t}}$, and $\mathrm{AUC}_{0 \text {-inf }}$ of lidocaine was 23\%, 23\%, and $37 \%$ lower for swimming vs normal conditions, but these differences are not expected to be clinically meaningful as they are within the expected variability observed for the product across different pharmacokinetic studies.

Table 3 Summary Statistics of Adhesion Performance Evaluation of Lidocaine Topical System I.8\% Under Swimming, Showering, and Normal Conditions

\begin{tabular}{|l|c|c|c|c|c|c|c|}
\hline Statistics & Treatment & N & Minimum & Maximum & Mean & SD & CV (\%) \\
\hline Mean Adhesion Score (\%) & Swimming & 23 & 84.10 & 99.75 & 94.73 & 4.19 & 4.4 \\
& Showering & 24 & 81.26 & 99.64 & 94.99 & 4.76 & 5.0 \\
& Normal & 23 & 88.59 & 99.99 & 97.11 & 2.55 & 2.6 \\
\hline
\end{tabular}

Note: Mean adhesion was calculated per the protocol adhesion assessment time points: 3, 4.5, 7, 8.5 and 12 hours.

Abbreviations: SD, standard deviation; CV, coefficient of variation. 
Table 4 Summary Statistics of Pharmacokinetic Parameters of Lidocaine Topical System I.8\% Under Swimming, Showering, and Normal Conditions

\begin{tabular}{|c|c|c|c|c|c|c|c|}
\hline \multirow[t]{2}{*}{ Treatment } & \multicolumn{7}{|c|}{ Pharmacokinetic Parameter (Mean \pm SD) } \\
\hline & $C_{\max }(n g / m L)$ & $\begin{array}{l}\text { AUC }_{0 \rightarrow t}{ }^{\#} \\
(\mathrm{ng} \mathrm{h} / \mathrm{mL})\end{array}$ & $\begin{array}{l}\text { AUC }_{0 \rightarrow \text { inf }} \\
(\mathrm{ng} \mathrm{h/mL)}\end{array}$ & $\begin{array}{c}\text { AUC\% Extra- } \\
\text { Polation }\end{array}$ & $\mathbf{T}_{\max }(\mathbf{h r})$ & $K_{e}^{\#}\left(h r^{-1}\right)$ & $T_{1 / 2}{ }^{\#}(h r)$ \\
\hline Swimming ${ }^{\Omega} N=22$ & $18.780 \pm 6.525$ & $249.432 \pm 88.233$ & $267.021 \pm 120.126$ & $9.900 \pm 4.452$ & $13.375 \pm 2.742$ & $0.1672 \pm 0.053$ & $4.403 \pm 0.961$ \\
\hline Showering $\mathbf{N}=\mathbf{2 4}$ & $27.213 \pm 18.987$ & $338.716 \pm 215.911$ & $448.265 \pm 302.209$ & $10.399 \pm 4.876$ & $12.006 \pm 3.426$ & $0.155 \pm 0.044$ & $4.751 \pm 1.131$ \\
\hline Normal $\mathbf{N}=\mathbf{2 3}$ & $24.538 \pm 11.083$ & $323.345 \pm 153.344$ & $425.799 \pm 159.0059$ & $|1.4| 2 \pm 5.69 \mid$ & $12.789 \pm 2.747$ & $0.152 \pm 0.0390$ & $4.831 \pm 1.131$ \\
\hline
\end{tabular}

Notes: ${ }^{\#}$ For Swimming, $\mathrm{N}=7$ for pharmacokinetic parameters of $A U C_{0-\text { inf, }} A U C_{\% \text { Extrapolation, }} \mathrm{K}_{\mathrm{e}}$ and $\mathrm{T}_{\mathrm{I} / 2}$ as subjects whose plasma concentrations did not exhibit the loglinear relationship at the terminal elimination phase as the as the $\mathrm{R} 2$ values were found to be less than 0.8 were excluded. ${ }^{\#}$ For Showering, $\mathrm{N}=15$ for pharmacokinetic parameters of $A \cup C_{0 \text {-inf, }} A \cup C \%$ Extrapolation, $K_{e}$ and $T_{1 / 2}$ as as subjects whose plasma concentrations did not exhibit the log-linear relationship at the terminal elimination phase as the as the R2 values were found to be less than 0.8 were excluded. ${ }^{*}$ For Normal, $N=12$ for pharmacokinetic parameters of $A U C_{0 \text {-inf, }} A U C \% E_{\text {Extrapolation, } K_{e} \text { and }}$ $T_{1 / 2}$ as subjects whose plasma concentrations did not exhibit the log-linear relationship at the terminal elimination phase as the as the R2 values were found to be less than 0.8 were excluded. ${ }^{\Omega}$ One subject was excluded from the PK and statistical analyses because the pre-dose plasma lidocaine concentration was more than $5 \%$ of $C_{\text {max }}$.

\section{Skin Irritation Assessments}

Skin irritation was assessed 30 minutes and 2 hours after the topical system was removed. The mean irritation scores at both 12.5 hours and 14 hours post-product application were less than 1 , which is not considered to be clinically significant (Table 6).

\section{Adverse Events}

A total of 15 AEs were spontaneously reported by 7 subjects during the study (Table 7); all were mild and were considered either unrelated or unlikely to be related to the study drug. The most common AE was headache, which occurred in 3 subjects. No deaths or serious AEs were reported during the study and no subjects discontinued due to an $\mathrm{AE}$.

\section{Discussion}

Water exposure can affect the ability of a topical system to adhere to the skin. While not specifically designed to be immersed in water, these data show that while water exposure can cause the lidocaine topical system $1.8 \%$ to lift or detach, the product is capable

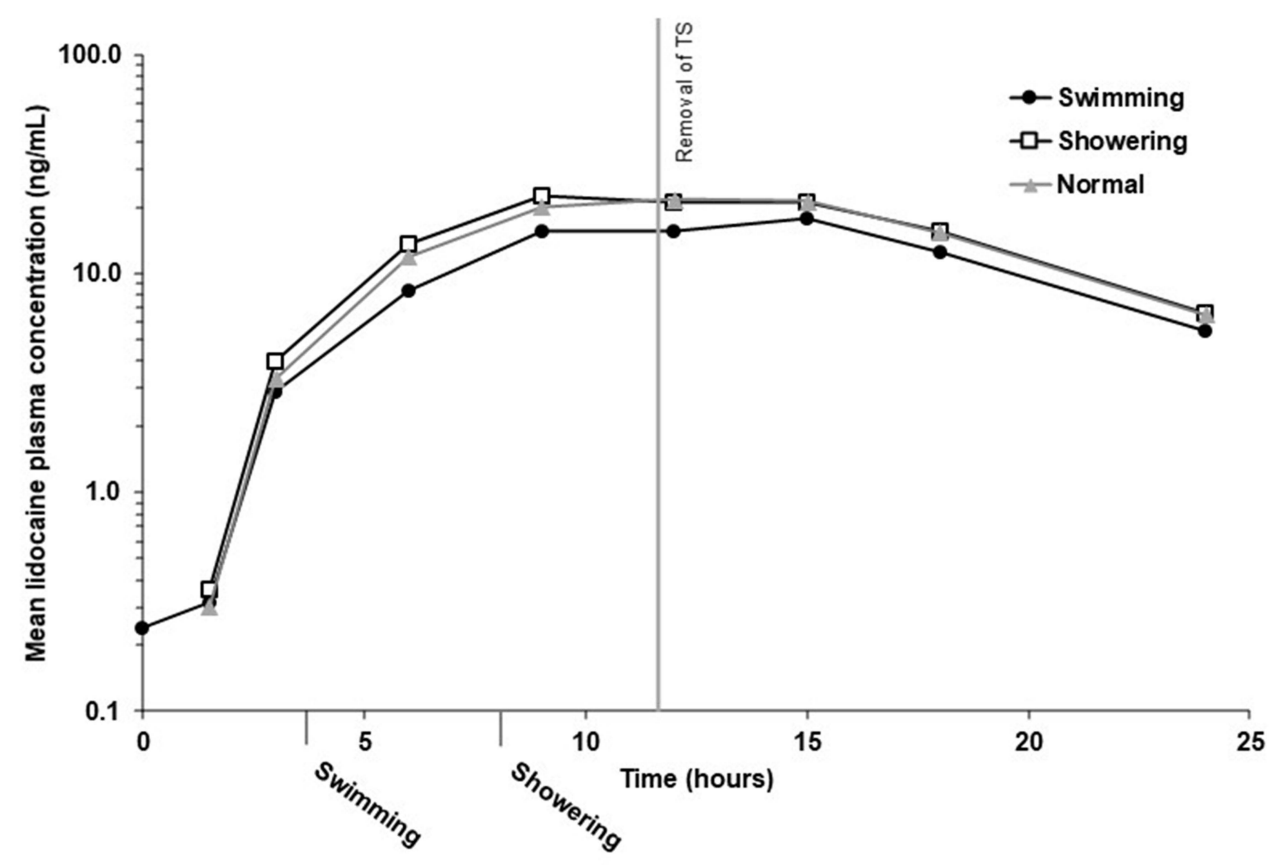

Figure 2 Mean plasma lidocaine concentration after application of one lidocaine topical system I.8\% vs time under swimming, showering, and normal conditions. 
Table 5 Geometric Least Square Mean, Ratios, 90\% Confidence Interval, ISCV and Power for Lidocaine Topical System I.8\% (Ln Transformed Data)

\begin{tabular}{|l|c|c|c|c|c|c|c|}
\hline \multirow{2}{*}{ Parameter } & \multicolumn{3}{|c|}{ Geometric Mean } & $\begin{array}{c}\text { (Swim/ } \\
\text { Normal) } \\
\text { Ratio, \% }\end{array}$ & $\begin{array}{c}\text { 90\% Confidence } \\
\text { Intervals (Swim/ } \\
\text { Normal) }\end{array}$ & $\begin{array}{c}\text { (Shower/ } \\
\text { Normal) } \\
\text { Ratio, \% }\end{array}$ & $\begin{array}{c}\text { 90\% Confidence } \\
\text { Intervals (Shower/ } \\
\text { Normal) }\end{array}$ \\
\cline { 2 - 7 } & Swimming & $\begin{array}{c}\text { Treatment } \\
\text { Showering }\end{array}$ & Normal & & & & \\
\hline $\mathrm{C}_{\max }, \mathrm{ng} / \mathrm{mL}$ & 17.8710 & 21.3466 & 21.9842 & 81.29 & $74.18-89.08$ & 97.10 & $88.76-106.23$ \\
$\mathrm{AUC}_{0-\mathrm{t}}, \mathrm{ng} \cdot \mathrm{h} / \mathrm{mL}$ & 237.5092 & 273.5891 & 287.7485 & 82.54 & $75.78-89.90$ & 95.08 & $87.43-103.40$ \\
$\mathrm{AUC}_{0-\infty}, \mathrm{ng} / \mathrm{mL}$ & 276.7251 & 313.8837 & 358.8316 & 77.12 & $64.25-92.7$ & 87.47 & $74.64-102.52$ \\
\hline
\end{tabular}

Table 6 Summary Irritation Analysis

\begin{tabular}{|c|c|c|c|c|c|c|}
\hline $\begin{array}{l}\text { Post-TS } \\
\text { Application Time }\end{array}$ & $\mathbf{N}$ & Mean & SD & Min & Median & $\operatorname{Max}$ \\
\hline \multicolumn{7}{|l|}{ Swimming } \\
\hline Baseline ( -0.5 hours) & 23 & 0 & 0 & 0 & 0 & 0 \\
\hline I2.5 Hours & 23 & 0.74 & 0.45 & 0 & 1 & 1 \\
\hline 14 Hours & 23 & 0.13 & 0.34 & 0 & 0 & 1 \\
\hline \multicolumn{7}{|l|}{ Showering } \\
\hline Baseline ( -0.5 hours) & 24 & 0 & 0 & 0 & 0 & 0 \\
\hline I2.5 Hours & 24 & 0.79 & 0.51 & 0 & 1 & 2 \\
\hline 14 Hours & 24 & 0.25 & 0.44 & 0 & 0 & I \\
\hline \multicolumn{7}{|l|}{ Normal Conditions } \\
\hline Baseline ( -0.5 hours) & 23 & 0 & 0 & 0 & 0 & 0 \\
\hline 12.5 Hours & 23 & 0.74 & 0.45 & 0 & 1 & 1 \\
\hline 14 Hours & 23 & 0.22 & 0.42 & 0 & 0 & 1 \\
\hline
\end{tabular}

Notes: Irritation scale: $0=$ no evidence of irritation; I=minimal erythema, barely perceptible; $2=$ definite erythema, readily visible, or minimal edema, or minimal popular response; $3=$ erythema and papules; $4=$ definite edema; $5=$ erythema, edema, and papules; $6=$ vesicular eruption; $7=$ strong reaction spreading beyond test site.

Abbreviations: TS, topical system; SD, standard deviation; Min, minimum; Max, maximum.

of being reapplied and maintains adhesion after brief water exposures for up to 12 hours, the labeled administration period.

The pharmacokinetic data confirm that there is no meaningful loss in product performance when the lidocaine topical system $1.8 \%$ used under the two water stress conditions (swimming and showering) relative to normal wear. These data also show that there is no dose-dump effect when the product is exposed to the higher water temperature associated with showering. While the product was not bioequivalent between the two water stress conditions and normal wear, the study was not designed or powered for bioequivalence and only involved a single topical system administration versus standard three topical systems incorporated in formal bioequivalence studies conducted previously. ${ }^{4}$ Specifically, the administration of a single topical systemic provides for a lower systemic level of drug that specifically did not allow for inclusion of all subject PK data across all periods in the $\mathrm{AUC}_{0 \text {-inf }}$ and

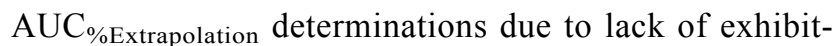
ing a log-linear relationship at the terminal elimination phase.

Limitations of the present study include the small size of the study population $(\mathrm{N}=24)$ and the lack of a comparator. Comparative assessment between lidocaine topical system $1.8 \%$ and lidocaine patch $5 \%$ would have been of interest as the effect of water on adhesion and drug delivery is dependent on several factors, including inactive ingredient composition, and therefore should be determined on a product-specific basis.

\section{Conclusion}

The results of this study show that immersing the lidocaine topical system $1.8 \%$ in water has the potential to increase product lifting and detachment; however, these data also show that wet topical systems can be successfully reapplied and remain adhered for up to the labeled administration period of 12 hours. These data also show the topical system may be used while showering and this does not increase lidocaine plasma levels as the $\mathrm{C}_{\max }$ and $\mathrm{AUC}_{0-\mathrm{t}}$ were similar to normal conditions. The topical systems were well tolerated under all conditions, and the dermal irritation profile was benign. 
Table 7 Summary of Treatment-Emergent Adverse Events

\begin{tabular}{|c|c|c|c|c|}
\hline System Organ Class & Preferred Term & Swimming & Showering & Normal \\
\hline Subjects with any $A E, n(\%)$ & & $3(13.0 \%)$ & $3(12.5 \%)$ & $4(17.4 \%)$ \\
\hline General disorders and administration site conditions, $\mathrm{n}(\%)$ & Injection site discomfort & $\begin{array}{c}\text { I }(4.3 \%) \\
N R=I(4.3 \%)\end{array}$ & $\begin{array}{c}\text { I }(4.2 \%) \\
N R=I(4.2 \%)\end{array}$ & $\begin{array}{c}2(8.7 \%) \\
N R=I(4.3 \%)\end{array}$ \\
\hline \multirow[t]{2}{*}{ Nervous system disorders } & Dizziness & $\begin{array}{c}\text { I }(4.3 \%) \\
N R=I(4.3 \%)\end{array}$ & 0 & 0 \\
\hline & Headache & 0 & $\begin{array}{c}\text { I }(4.2 \%) \\
\text { UR=I }(4.2 \%)\end{array}$ & $\begin{array}{c}2(8.7 \%) \\
U R=I(4.3 \%) \\
N R=I(4.3 \%)\end{array}$ \\
\hline \multirow[t]{3}{*}{ Gastrointestinal disorders } & Nausea & $\begin{array}{c}\text { I }(4.3 \%) \\
N R=I(4.3 \%)\end{array}$ & $\begin{array}{c}\text { I }(4.2 \%) \\
\text { UR=I }(4.2 \%)\end{array}$ & 0 \\
\hline & Diarrhea & $\begin{array}{c}\text { I }(4.3 \%) \\
\text { UR=I }(4.3 \%)\end{array}$ & 0 & 0 \\
\hline & Abdominal pain, upper & 0 & $\begin{array}{c}\text { I }(4.2 \%) \\
\text { UR=I }(4.2 \%)\end{array}$ & 0 \\
\hline Skin and subcutaneous tissue disorders & Pallor & $\begin{array}{c}\text { I }(4.3 \%) \\
N R=I(4.3 \%)\end{array}$ & 0 & 0 \\
\hline \multirow[b]{2}{*}{ Musculoskeletal and connective tissue disorders } & Cold sweat & $\begin{array}{c}\text { I }(4.3 \%) \\
N R=I(4.3 \%)\end{array}$ & 0 & 0 \\
\hline & Neck pain & 0 & 0 & $\begin{array}{c}\text { I }(4.3 \%) \\
N R=I(4.3 \%)\end{array}$ \\
\hline
\end{tabular}

Notes: Counts reflect numbers of subjects reporting one or more AEs that map to the MedDRA preferred term. AEs were analyzed based on the last treatment subjects were on prior to $A E$ occurrence. Denominator for percentages was number of subjects exposed to the given treatment.

Abbreviations: AE, adverse event; MedDRA, Medical Dictionary for Regulatory Activities; NR, not related; UR, unlikely related.

\section{Data Sharing Statement}

The authors certify that this manuscript reports original clinical trial data. Individual participant data that underlie the results reported in this article after deidentification (text, tables, and figures) are available, including the study protocol. Data requests should be submitted in the form of a research proposal to medical_affairs@scilexpharma.com for up to 36 months after the publication date.

\section{Acknowledgments}

The authors would like to thank Peter Boldingh, PharmD, the staff at Axis Clinicals, and the study volunteers who made this study possible.

\section{Funding}

This study was funded by Scilex Pharmaceuticals Inc.

\section{Disclosure}

Dr Patel and Dr Lissin are full-time employees of Scilex Pharmaceuticals Inc. Mr Vought was an employee of
Scilex Pharmaceuticals Inc at the time the study was conducted. Dr. Greuber was an employee of Scilex Pharmaceuticals Inc. at the time the study was conducted and is currently with Regulatory and Strategic Development, Clinipace, Inc., Morrisville, NC, USA. Dr Charles Argoff reports personal fees from Scilex, BDSI, Biohaven, Nevro, Amgen, and Novartis; grants, personal fees from AbbVie, Teva, Lilly, and Flowonix; royalties for book publication from Elsevier, outside the submitted work. This article is the sole work of the authors; stated opinions or assertions do not reflect the opinions of employers or employee affiliates listed. The authors report no other conflicts of interest in this work.

\section{References}

1. Nalamachu S, Gudin J. Characteristics of analgesic patch formulations. J Pain Res. 2020;13:2343-2354. doi:10.2147/JPR. S270169

2. Gudin J, Nalamachu S. Utility of lidocaine as a topical analgesic and improvements in patch delivery systems. Postgrad Med. 2020;132 (1):28-36. doi:10.1080/00325481.2019.1702296 
3. ZTLIDO $^{\circledR}$ (lidocaine topical system): prescribing information. San Diego, California, USA: Scilex Pharmaceuticals; 2018.

4. Gudin J, Argoff C, Fudin J, et al. A randomized, open-label, bioequivalence study of lidocaine topical system $1.8 \%$ and lidocaine patch 5\% in healthy subjects. J Pain Res. 2020;13:1485-1496. doi: $10.2147 /$ JPR.S237934

5. Shrestha M, Chen A. Modalities in managing postherpetic neuralgia. Korean J Pain. 2018;31(4):235-243. doi:10.3344/kjp.2018.31.4.235

6. Massengill JS, Kittredge JL. Practical considerations in the pharmacological treatment of postherpetic neuralgia for the primary care provider. J Pain Res. 2014;7:125-132. doi:10.2147/JPR.S57242

7. Wokovich AM, Prodduturi S, Doub WH, et al. Transdermal drug delivery system (TDDS) adhesion as a critical safety, efficacy and quality attribute. Eur $J$ Pharm Biopharm. 2006;64(1):1-8. doi:10.1016/j.ejpb.2006.03.009

8. Cilurzo F, Gennari CG, Minghetti P. Adhesive properties: a critical issue in transdermal patch development. Expert Opin Drug Deliv. 2012;9(1):33-45. doi:10.1517/17425247.2012.637107

9. Strasinger C, Raney SG, Tran DC, et al. Navigating sticky areas in transdermal product development. $J$ Control Release. 2016;10 (233):1-9.

10. Guidance for Industry. Assessing adhesion with transdermal and topical delivery systems for ANDAs. U.S. Department of Health and Human Services, Food and Drug Administration, ed. Rockville, MD, USA; 2018. Available from: https://www.fda.gov/media/ 117569/download. Accessed August 2, 2021.
11. Vanakoski J, Seppala T. Heat exposure and drugs: a review of the effects of hyperthermia on pharmacokinetics. Clin Pharmacokinet. 1998;34(4):311-322. doi:10.2165/00003088-199834040-00004

12. Fudin J, Wegrzyn E, Greuber E, et al. A randomized, crossover, pharmacokinetic and adhesion performance study of a lidocaine topical system $1.8 \%$ during physical activity and heat treatment in healthy subjects. $J$ Pain Res. 2020;13:1359-1367. doi:10.2147/JPR. S238268

13. Gudin J, Webster LR, Greuber E, Vought K, Patel K, Kuritzky L. Open-label adhesion performance studies of a new lidocaine topical system $1.8 \%$ versus lidocaine patches $5 \%$ and lidocaine medicated plaster 5\% in healthy subjects. J Pain Res. 2021;14:513-526. doi:10.2147/JPR.S287153

14. Guidance for Industry. Assessing the irritation and sensitization potential of transdermal and topical delivery systems for ANDAs. U.S. Department of Health and Human Services, Food and Drug Administration, ed. Rockville, MD, USA; 2018. Available from: https://www.fda.gov/media/117569/download. Accessed August 2, 2021.

\section{Publish your work in this journal}

The Journal of Pain Research is an international, peer reviewed, open access, online journal that welcomes laboratory and clinical findings in the fields of pain research and the prevention and management of pain. Original research, reviews, symposium reports, hypothesis formation and commentaries are all considered for publication. The manuscript management system is completely online and includes a very quick and fair peer-review system, which is all easy to use. Visit http:// www.dovepress.com/testimonials.php to read real quotes from published authors. 